\title{
COGNITIVE THERAPY AND LOGOTHERAPY ON DEPRESSION OF PATIENTS WITH TYPE 2 DIABETES MELLITUS
}

\author{
Sutinah Sutinah ${ }^{1 *}$ \\ ${ }^{1}$ STIKES Harapan Ibu, Jambi \\ Email*: Ns.titin@yahoo.com
}

\begin{abstract}
Introduction: Diabetes mellitus (DM) is a severe health disorder that causes physical problems and psychosocial effects. Depression and anxiety are the most common psychosocial problems experienced by people with DM. The purpose of this study was to determine the impact of cognitive therapy and logotherapy on and anxiety in patients with Type 2 diabetes. Methods: A quasi-experimental design has been conducted for the study at a hospital in Jambi Province. The total sample of 90 respondents with a consecutive sampling method. The independent variables are cognitive therapy and logotherapy, while the dependent variables are depression and anxiety. Data were analyzed by paired sample t-test and ANOVA. Results: The results showed that cognitive therapy and logotherapy could reduce depression more than giving cognitive therapy alone with a p-value of 0.0005. Conclusions: Cognitive therapy and logotherapy can be standard therapy in dealing with patients with psychosocial problems.
\end{abstract}

Keywords: cognitive therapy; depression; diabetes mellitus; logotherapy; psychosocial

\section{INTRODUCTION}

Psychosocial problems that are often experienced by clients of diabetes mellitus (DM) are depression. Seventy-nine percent of people with diabetes experience depression. Some patients become agitated, anxious, and hyperactive. Others can become withdrawn and no longer active. Most chronic diseases that weaken the body are often accompanied by depression, many depressive incidents are found in people who experience physical disorders and chronic physical illnesses such as DM disease caused by the medical conditions they experience. Medical conditions that can cause anxiety such as hypoglycemia in endocrine dysfunction. Depression can worsen the physical health condition of DM clients (Varcarolis, E.M. and Halter, 2010). Patients tend to experience stress and depression in the face of management of DM; the feeling of anxiety and depression makes DM patients do not obey the dietary rules recommended by health workers. Thus it is clear that depression conditions in DM clients can interfere with treatment management in DM clients (Isabella, Sitorus, \& Afiyanti, 2008).
Diabetic patients have episodes of anxiety that around $50 \%$ to $76 \%$ of depressed patients experience anxiety (Alladin, 2009). When the body's anxiety reduces and increases glycogenolysis to free glucose to support the heart, muscles and central nervous system (Varcarolis, E.M. and Halter, 2010). So in DM clients who experience anxiety, clients easily forget about diet and treatment programs. Therefore, to prevent physical hazards that can be caused by depression and anxiety problems encountered by DM clients, in addition to pharmacological therapy, DM clients must also receive psychotherapy. Individual psychotherapy that can be given to patients with depression and anxiety includes cognitive therapy and logotherapy (Livermore, N., Sharpe, L., \& McKenzie, 2008).

Cognitive therapy can also help individuals cope with anxiety responses due to the distortion of negative thoughts (Rupke, S.J., Blecke, D., \& Renfrow, 2006). Depressive condition decreased more significantly in the group of chronic kidney failure patients who received cognitive therapy compared to the group of chronic kidney failure patients who did not get cognitive therapy (Hollon, S.D., 
Kendall, 2009). The purpose of cognitive therapy is to monitor negative automatic thoughts, find out the relationship between thoughts, feelings, and behavior, change wrong reasoning into logical reasoning and help patients identify and change false beliefs as negative internal experiences of patients (Varcarolis, E.M. and Halter, 2010).

Logotherapy can overcome depression in adolescents (Schulenberg, S. E., Hutzell, R. R., Nassif, C., \& Rogina, 2008). A decrease in the condition of depression in the elderly, which was more significant in the group who were given logotherapy and family psychoeducation than the group that was only given family psychoeducation (Chang, 2002). In addition, research conducted by Kyrios, M., Mouding, R., \& Nedelkovic (2011) about the effect of group logotherapy on anxiety in postearthquake populations found a more significant decrease in anxiety in the group that was given logotherapy (Kyrios, M., Mouding, R., \& Nedelkovic, 2011). Based on the description above, research related to cognitive therapy and logotherapy interventions needs to be done in patients with diabetes mellitus who experience anxiety. The purpose of this study was to determine the effectiveness of cognitive therapy and logotherapy on reducing depression in patients with diabetes mellitus.

\section{METHODS}

This study uses a quasi-experimental design with a nonequivalent control group design. The study was conducted from February to July 2017 for six weeks. The location of the study was in the Internal Medicine Section of a Hospital in Jambi Province, Indonesia.

The target population in this study were all 106 types, 2 DM clients. The sample in this study were DM clients who were hospitalized with inclusion criteria as follows: 1) clients who were undergoing hospitalization diagnosed with type $2 \mathrm{DM} ; 2$ ) age range 20-65 years; 3) experiencing depression and/or anxiety; 4) Can read and write; 5) communicative, cooperative, the client does not experience a decrease in awareness during the study; 6) willing to be a respondent. A total sample of 90 respondents (29 people for the cognitive therapy and logotherapy intervention groups (intervention 1), 31 people for the intervention group with cognitive therapy (intervention 2), and 30 people for the control group). The sampling technique used in this study is non-probability sampling with the consecutive sampling method.

The demographic instruments consisted of age, sex, education, marital status, occupation, income, and duration of DM. This study uses the Hospital Anxiety And Depression Scale (HADS) instrument (Steger, 2009) to measure the condition of depression and anxiety. Test instruments in this study used Pearson product-moment correlation test with Cronbach's alpha value of 0.763 . The questionnaire consisted of 14 questions with a Likert scale $(0-3)$. Unfavorable questions: 3 = never, 2 = rarely, $1=$ sometimes, and $0=$ often. Favorable statements with a scale value of $3=$ often, 2 $=$ Sometimes, $1=$ rarely, and $0=$ never. The total HADS Questionnaire Score is $0-21(\geq 11$ depression or anxiety, $8-10$ : risk, $\leq 7$ : healthy or not depressed or anxiety)

The study was conducted after being declared ethical and complying with the research code of ethics. The research phase consisted of the pre-test stage, with respondents filling out questionnaires to determine the condition of depression and anxiety experienced by DM clients. The intervention phase consists of intervention group 1 (cognitive therapy and individual logotherapy). Researchers provide cognitive therapy then proceed with individual logotherapy. Therapeutic activities carried out every day. Cognitive therapy consists of 5 sessions with five meetings, while logotherapy consists of 4 sessions with $4 \mathrm{x}$ meetings. Each session is done for 30 minutes. Intervention group 2 (cognitive 
therapy). Therapeutic activities carried out every day. Cognitive therapy consists of 5 sessions with each session for 30 minutes. The control group was not given therapy but given a booklet that contained stress management to deal with depression and anxiety. In the posttest stage, questionnaires were given back to evaluate changes in depression and anxiety in the three groups.
The analysis was performed using paired sample t-tests and ANOVA. This study has passed the ethical test from the Health Research Ethics Commission of the University of Jambi with number 95 / UN18.4 / LT / 2017 on April 3, 2017. This study has followed the research code of ethics.

\section{RESULTS}

Table 1. Characteristics of respondents $(n=90)$

\begin{tabular}{|c|c|c|c|c|c|c|c|c|c|}
\hline \multirow[t]{2}{*}{ Characteristic } & \multicolumn{2}{|c|}{$\begin{array}{c}\text { Intervention } 1 \\
(\mathrm{n}=29)\end{array}$} & \multicolumn{2}{|c|}{$\begin{array}{c}\text { Intervention } 2 \\
\quad(\mathbf{n}=\mathbf{3 1})\end{array}$} & \multicolumn{2}{|c|}{ Control (30) } & \multicolumn{2}{|c|}{ Total } & \multirow[t]{2}{*}{ p-value } \\
\hline & $\mathbf{n}$ & $\%$ & $\mathbf{n}$ & $\%$ & $\mathbf{n}$ & $\%$ & $\mathbf{n}$ & $\%$ & \\
\hline \multicolumn{10}{|l|}{ Gender } \\
\hline Male & 8 & 27.6 & 17 & 54.8 & 16 & 53.3 & 41 & 45.6 & 0.061 \\
\hline Female & 21 & 72.4 & 14 & 45.2 & 14 & 46.7 & 49 & 54.4 & \\
\hline \multicolumn{10}{|l|}{ Occupation } \\
\hline Worked & 18 & 62.1 & 23 & 74.2 & 22 & 73.3 & 63 & 70.0 & 0.525 \\
\hline No worked & 11 & 37.9 & 8 & 25.8 & 8 & 26.7 & 27 & 30.0 & \\
\hline \multicolumn{10}{|l|}{ Income } \\
\hline Under MWR & 15 & 51.7 & 13 & 41.9 & 12 & 40.0 & 40 & 44.4 & 0.625 \\
\hline Above MWR & 14 & 48.3 & 18 & 58.1 & 18 & 60.0 & 50 & 55.6 & \\
\hline \multicolumn{10}{|l|}{ Education } \\
\hline $\begin{array}{l}\text { Elementary and junior high } \\
\text { school }\end{array}$ & 17 & 58.6 & 10 & 32.3 & 10 & 33.3 & 37 & 41.1 & 0.066 \\
\hline $\begin{array}{l}\text { Senior high school and } \\
\text { university }\end{array}$ & 12 & 41.4 & 21 & 67.7 & 20 & 66.7 & 53 & 58.9 & \\
\hline \multicolumn{10}{|l|}{ Marital Status } \\
\hline Married & 16 & 55.2 & 23 & 74.2 & 22 & 73.3 & 61 & 67.8 & 0.210 \\
\hline Unmarried & 13 & 44.8 & 8 & 25.8 & 8 & 26.7 & 29 & 32.2 & \\
\hline MWR: Minimum Wage Rate & & & & & & & & & \\
\hline
\end{tabular}

Table 2. Cognitive intervention therapy and logotherapy for depression and anxiety in type 2 DM patients $(\mathbf{n}=\mathbf{9 0})$

\begin{tabular}{lcccccccc}
\hline Variables & $\mathbf{n}$ & $\begin{array}{c}\text { Pre } \\
(\text { Mean } \pm \text { SD })\end{array}$ & $\begin{array}{c}\text { Post } \\
(\text { Mean } \pm \text { SD })\end{array}$ & $\mathbf{p}^{*}$ & Delta & Min \pm Max Mean \pm SD & $\mathbf{p}^{* *}$ \\
\hline Depression & & & & & & & & \\
Treatment 1 & 29 & $14.55 \pm 2.25$ & $3.00 \pm 2.25$ & 0.005 & $11.55 \pm 1.18$ & $0-8$ & $3.00 \pm 1.79$ & \\
Treatment 2 & 31 & $13.81 \pm 2.33$ & $3.87 \pm 2.28$ & 0.005 & $9.94 \pm 1.32$ & $1-8$ & $3.87 \pm 2.28$ & 0.005 \\
Control & 30 & $13.67 \pm 1.99$ & $9.93 \pm 1.17$ & 0.005 & $3.73 \pm 1.14$ & $8-12$ & $1.17 \pm 0.21$ & \\
Anxiety & & & & & & & & \\
Treatment 1 & 29 & $17.31 \pm 1.39$ & $5.45 \pm 1.55$ & 0.005 & $11.86 \pm 1.18$ & $2-8$ & $5.45 \pm 1.55$ & \\
Treatment 2 & 31 & $16.6 \pm 2.00$ & $7.13 \pm 1.88$ & 0.005 & $8.94 \pm$ & $3-11$ & $7.13 \pm 1.88$ & 0.005 \\
& & & & & 1.75 & & & \\
Control & 30 & $15.83 \pm 1.64$ & $11.37 \pm 2.56$ & 0.005 & $4.47 \pm 1.33$ & $7-15$ & $11.37 \pm 1.56$ & \\
\hline
\end{tabular}

Treatment 1: Cognitive therapy and logotherapy

Treatment 2: Cognitive therapy

$p^{*}$ Paired t-test (normal p-value 0.05)

$p^{* *}$ ANOVA (p-value 0.05) 
DM client characteristics in the form of gender, education, employment, income, and marital status of DM clients were analyzed using frequency distribution and equality analysis between the three groups using the chi square test, showing 49 respondents $(54.4 \%)$ were female, 63 people ( 70.0\%) work with 50 people (55.6\%) earning above the minimum wage, 52 people $(57.8 \%)$ have high education, and 61 people $(67.8 \%)$ are married. At alpha 0.05 sex, occupation, income, education, and marital status between groups who received cognitive therapy and logotherapy, groups that only received cognitive therapy, and groups that did not get therapy were equivalent, see table 1 .

Changes in the depression condition of DM clients before and after the intervention given to the group who received cognitive therapy and logotherapy, the group that only received cognitive therapy, and the group that did not get therapy were analyzed using paired t-test with $\alpha 0.05$. It appears that at $\alpha 0.05$ there was a change in significant depressive conditions in the three groups before and after the intervention, where depression conditions for DM clients after the intervention in the group that received cognitive and logotherapy from a score of 14.55 (depressive condition) to 3.00 (noncase depression), in the group that only received cognitive therapy from the score 13.81 (depression) to 3.87 (non-case depression), and in the group that did not get therapy from a score of 13.67 (depression) to 9.93 (risk of depression) $(\mathrm{p}<0.05)$.

Changes in the condition of DM client anxiety before and after intervention in the group that received cognitive therapy and logotherapy, the group that only received cognitive therapy, and the group that did not get therapy using paired t-test analysis with alpha 0.05 , showed that in alpha 0.05 there was a significant change in conditions anxiety before and after intervention in all three groups. The average change in the condition of DM client anxiety before and after intervention in the group receiving cognitive therapy and logotherapy was 11.86 , from 17.31 (anxiety) to 5.45 (non-case anxiety), in the group that only received cognitive therapy at 8.94, from 16.6 (anxiety ) to 7.13 (non-case anxiety) and in the group that did not receive therapy by 4.47 , from 15.38 (anxiety) to 11.37 (anxiety).

\section{DISCUSSIONS}

The results showed that $79 \%$ of DM clients who were hospitalized experienced depression and anxiety. This is consistent with the explanation of Varcarolis, E.M. and Halter (2019) that DM can cause psychological changes such as changes in mental processes, behavior, and neurological functions that cause clients to be quiet, anxious, withdrawn, and no longer active in social relationships (Varcarolis, E.M. and Halter, 2010). DM is a chronic disease that weakens the body, which can cause depression and anxiety in sufferers (Suddarth, 2010).

Many factors can cause DM clients to experience depression and anxiety, among others, it can be caused by biochemical changes in the body of DM sufferers and the therapy that the client goes through. Biochemical changes that occur in people with DM are the same as those that occur in depression, namely the increase in the hormone cortisol and disorders of the metabolism of epinephrine and norepinephrine. Increased cortisol, epinephrine, and norepinephrine hormones are triggered due to an increase in glucose levels in the blood so that DM clients experience mood disorders, as seen in symptoms of depression and anxiety. Therapy that must be done routinely also causes boredom and pressure on the client, which causes the client to feel different from others and ultimately cause symptoms of depression and anxiety. Signs and symptoms of DM can also cause depression and anxiety. DM clients will tend to experience three 
typical symptoms, namely polyuria, polydipsia, and polyphagia. Psychological signs and symptoms caused by these clinical manifestations are signs and symptoms of depression. This was found in DM clients at the time of the study where the average DM client was anxiously divorced by his partner, felt useless because he could not carry out his role as usual, felt worthless because he could not make something proud, felt sad could not be happy partner, the body feels weak and tired, so it is not eager to do something (Suddarth, 2010).

Complications experienced by DM clients can also cause depression and anxiety. Complications caused can be in the form of acute complications and chronic complications. As a result of these complications, the client becomes quiet, withdrawn, irritable, and offended, ashamed of the physical conditions experienced and feels himself making trouble for others, worrying about the future, feeling sad, and troublesome for the family, causing depression and anxiety for DM clients. DM management that DM clients must undergo throughout their lives can also lead to depression and anxiety in DM clients. There are four pillars of DM management that must be lived by DM clients throughout their lives, namely planning diets, physical exercise, hypoglycemic drugs, and counseling. Continuous insulin injections or oral hypoglycemic drugs that must be taken daily, routine blood sugar level checks, and the need for regular physical exercise lead to new lifestyle changes where these changes make DM clients feel they have no freedom in life so arouse boredom, hopelessness, and helplessness (Suddarth, 2010). This is often found in DM clients who are respondents of research, where it makes clients become depressed, and anxiety lead a different life with others (Varcarolis, E.M. and Halter, 2010).

Logotherapy is a search for life meaning psychotherapy in any condition so that the client can survive in life by improving the quality of life. This is in accordance with the statement explaining logotherapy is psychotherapy that aims to achieve meaningful life by understanding the conditions both physically and spiritually by motivating that every human being has the potential to live meaningfully (Rupke, S.J., Blecke, D., \& Renfrow, 2006). Logotherapy can help overcome the problem of depression (Southwick et al., 2006).

Signs and symptoms that can be found in individuals who do not have the meaning of life are empty feelings, sad, depressed, do not have a purpose in life, apathetic, feel useless, and feel bored (Rupke, S.J., Blecke, D., \& Renfrow, 2006). DM clients who experience depression and anxiety also find feelings of sadness, anxiety, sleep disturbances, hopelessness, helplessness, loss of interest, lack of enthusiasm, lazy activity, resulting in decreased meaning and quality of life. This is a sign and symptom of depression and anxiety. Thus logotherapy is a therapy that can also be given to depressed clients.

Cognitive therapy is also able to overcome the problem of depression and anxiety, as the principles of cognitive therapy are explained (Varcarolis, E.M. and Halter, 2010) that cognitive therapy teaches clients to identify, evaluate, and respond to distorted thoughts and beliefs so that this can help clients understand the importance of recognizing negative thoughts and turning them into positive thoughts that are in accordance with the client's current condition. Cognitive therapy is effective in dealing with depression that focuses on the modification of cognitive distortion and corrects maladaptive thoughts and changing negative thoughts (Oei \& Browne, 2006).

Depressed and anxiety clients often experience negative thoughts that lead to a loss of passion in the client's life. Negative thoughts on depression are automatic thoughts with perceptions and beliefs that are centered on negative attitudes toward the past, self, and future, while negative thoughts 
on anxiety are automatic thoughts that focus on the presence of danger (Varcarolis, E.M. and Halter, 2010). Someone in a state of urgency or in a bad situation experienced at this time tends to cause negative thoughts where negative thoughts are not defined rationally and logically correct. This is often found in DM clients in this study, such as troublesome thoughts, disturbing the comfort of the environment, being a burden on the family, useless, and thinking there is no hope anymore.

Clients who experience emotional disturbances such as depression and anxiety tend to experience negative automatic thoughts, where the client has emotional responses that lead to negative thoughts that are automatically stored in his memory without being analyzed rationally and logically (Kraus, 2009). Individuals who have negative thoughts are characterized by feelings of being unable to adjust to the desire to make changes in life, have negative expectations and negative self-concepts, low self-esteem, and give up easily (Hollon, S.D., Kendall, 2009). This was also found in DM clients in the study.

Each session in cognitive therapy is able to help DM clients understand the conditions they are experiencing so that clients felt the effects of this therapy in overcoming the problems of depression and anxiety. Cognitive therapy emphasizes the difficulties encountered by clients, so that motivates clients to identify negative thoughts and change the wrong ideas and beliefs towards more reality (Alladin, 2009). Thus, cognitive therapy can provide good effectiveness in overcoming the problems of depression and anxiety. This is evident during the administration of cognitive therapy the client realizes through his expression that the family is still caring and alternately visits the client, the couple is still affectionate and faithfully accompanying the client and is still able to meet the needs of the client's daily life and the client's care needs during the hospital. Changes to emotional responses and feelings of clients are much better than before getting cognitive therapy.

\section{CONCLUSIONS}

Giving cognitive therapy and logotherapy significantly reduces the condition of depression and anxiety. Jambi Hospital should have a particular room in the inpatient room to conduct cognitive therapy and logotherapy and should improve the quality of nursing care comprehensively through the recruitment of nurses who are competent in providing specialist mental therapy

\section{REFERENCES}

Alladin, A. (2009). Evidence Based Cognitive Hypnotherapy for Depression. International Symposium on Homogeneous Catalysis, 26(4), 245-262.

Chambless, D. L., Goldstein, A. J., Gallagher, R., \& Bright, P. (2010). Integrating behavior therapy and psychotherapy in the treatment of agoraphobia. Psychotherapy: Theory, Research, Practice, Training, 23(1), 150-159.

Chang, J. K. N. E. C. (2002). The positive psychology of negative thinking. Journal Of Clinical Psychology, 58(9), 993-1001.

Guha, M. (2010). The International Encyclopedia of Depression. Emerald Insight, 24(3), 37-39.

Hollon, S.D., Kendall, P. . (2009). Cognitive self-statements in depression: Development of an automatic thoughts questionnaire. Cogn Ther Res, 4, 383395.

Ingram, R. E., \& Wisnicki, K. S. (2011). Assessment of positive automatic cognition. Journal of Consulting and Clinical Psychology, 56(6), 898-902.

Isabella, C., Sitorus, R., \& Afiyanti, Y. (2008). Pengalaman Ketidakpatuhan Pasien Terhadap Penatalaksanaan Diabetes Mellitus: Studi Fenomenologi. Jurnal Keperawatan Indonesia, 12(2), 84-90. https://doi.org/10.7454/jki.v12i2.205 
Kraus, S. (2009). Five Steps for Declaring Independence from Negative Thinking. University of: Virginia Press.

Kyrios, M., Mouding, R., \& Nedelkovic, M. (2011). Anxiety Disorder: Assessment and Management in General Practice. Australian Family Physician, 40(6), 370374.

Livermore, N., Sharpe, L., \& McKenzie, D. (2008). Cognitive Behavioral Therapy for Panic Disorder in Chronic Obstructive Pulmonar Disease: Two Case Studies. Behavioural and Cognitive Psychotherapy, 36(5), 625-630.

Oei, T. P. S., \& Browne, A. (2006). Components of group processes: Have they contributed to the outcome of mood and anxiety disorder patients in a group cognitive-behaviour therapy program? American Journal of Psychotherapy, 60(1), 53-70. https://doi.org/10.1176/appi.psychothera py.2006.60.1.53

Rupke, S.J., Blecke, D., \& Renfrow, M. (2006). Cognitive Therapy for Depression. New York: tHE Guilford Press.

Schulenberg, S. E., Hutzell, R. R., Nassif, C., \& Rogina, J. M. (2008). Logotherapy for clinical practice. Psychotherapy: Theory, Research, Practice, Training, 45(4), 447463.

Southwick, S. M., Gilmartin, R., Mcdonough, P., \& Morrissey, P. (2006). Logotherapy as an adjunctive treatment for chronic combat-related PTSD: A meaning-based intervention. American Journal of Psychotherapy, 60(2), 161-174. https://doi.org/10.1176/appi.psychothera py.2006.60.2.161

Spek, V., D. (2007). Internet-Based Cognitive Behavior Therapy for Symptoms of Depression and Anxiety: a MetaAnalysis. Psychological Medicine, 37(3), 319-328.

Steger, M. (2009). Meaning in Life, Anxiety, Depression, and General Health Among Smoking Cessation Patients. Journal of Psychosomatic Research, 67(4), 353-358. Suddarth, B. and. (2010). Text Book Of Medical Surgical Nursing (12th ed.). China: LWW.

Varcarolis, E.M. and Halter, M. . (2010). Foundations of Psychiatric Mental Health Nursing: A Clinical Approach (6, ed.). St. Louis, Missouri: Saunders Elsevier. 